\title{
Sistem Pakar Diagnosa Fobia Menggunakan Metode Certainty Factor
}

\author{
Phobia Diagnosis Expert System Using Certainty Factor Method
}

\author{
Gita Prastianingrum ${ }^{1}$, Agus Sidiq Purnomo² \\ ${ }^{1,2}$ Program Studi Teknik Informatika, Fakultas Teknologi Informasi, Universitas Mercu Buana Yogyakarta, \\ J1. Wates Km. 10 Yogyakarta 55753, Indonesia \\ Email: ${ }^{1}$ gita@gmail.com, ${ }^{2}$ sidiq@mercubuana-yogya.ac.id
}

\begin{abstract}
ABSTRAK
Seseorang yang bereaksi dengan ketakutan yang amat sangat pada suatu stimulus atau situasi yang menurut kebanyakan orang lain tidaklah sangat berbahaya, disebut orang yang mempunyai fobia. Sebagai orang tua kita seharusnya waspada mengenai gejala-gejala fobia ini sedari dini dan mampu mengupayakan cara penanganannya secara tepat. Mengingat hal itu maka pada penelitian ini akan dibuat sebuah aplikasi untuk dapat mengidentifikasi seseorang mengidap fobia atau tidak. Observasi akan dilakukan melalui kusioner. Dengan setiap jawaban akan mempunyai nilai terhadap gejala-gejala fobia tersebut. Tahap pertama adalah pengambilan data. Dari 45 responden didapatkan data kuesioner yang kemudian diproses dengan statistik melalui sistem. Metode yang digunakan dalam sistem ini adalah Certainty Factor. Aplikasi ini menggunakan 45 data. Efektifitas pengujian mencapai hasil dimana hasil uji pakar dengan hasil uji sistem adalah sama. Dengan hasil persentase $10 \%$ untuk pasien yang tidak mengidap fobia, $40 \%$ untuk tingkat resiko ringan, $47 \%$ untuk tingkat resiko sedang, dan 9 $\%$ untuk tingkat resiko berat. Diharapkan penelitian ini dapat disempurnakan dan dikembangkan serta membantu menjadikan aplikasi konsultasi penanganan fobia ke seluruh masyarakat secara cumacuma.
\end{abstract}

Kata kunci: Certainty Factor, Fobia, Sistem Pakar.

\begin{abstract}
Someone who reacts with extreme fear in a stimulus or situation which according to most others is not very dangerous, is called a person who has a phobia. As parents we should be vigilant about the symptoms of this phobia from an early age and be able to work on how to handle it appropriately. Given this, in this study an application will be made to be able to identify someone have a phobia or not. Observation will be done through questionnaire. With each answer will have value for the symptoms of the phobia. The first stage is data collection. From 45 respondents, questionnaire data were obtained which were then processed with statistics through the system. The method used in this system is Certainty Factor. This application uses 45 data. Test effectiveness reaches results where expert test results with system test results are the same. With a percentage of $10 \%$ for patients who do not have phobias, $40 \%$ for mild risk levels, $47 \%$ for moderate risk levels, and $9 \%$ for severe risk levels. It is hoped that this research can be refined and developed as well as helping to make the application for phobia handling consultation to the entire community free of charge.
\end{abstract}

Keywords: Certainty Factor, Expert Systems, Phobias.

\section{PENDAHULUAN}

Fobia adalah termasuk kedalam psikoneurosis, tetapi berbeda dengan ganguan kecemasan merata, gangguan fobia mengandung ketakutan yang cukup spesifik. Seseorang yang bereaksi dengan ketakutan yang amat sangat pada suatu stimulus atau situasi yang menurut kebanyakan orang lain tidaklah sangat berbahaya disebut orang yang mempunyai fobia. Orang tersebut menyadari bahwa ketakutannya itu tidak rasional tetapi tetap merasakan kecemasan (mulai dari serba salah yang amat tinggi sampai panik) yang hanya dapat diredakan dengan menghindari benda atau situasi yang menakutkan itu (Yunita, 2018).

Sebagian besar kita takut pada sesuatu seperti : ular, tempat yang tinggi, angin 
kencang, dokter, sakit, luka, dan kematian merupakan tujuah rasa takut yang paling umum yang dilaporkan oleh orang-orang dewasa dan tampaknya terdapat suatu rangkaian antara rasa takut yang umum dengan fobia yang membuat perbedaan diagnosis gangguan fobia dan rasa takut umum apabila rasa takut tersebut tidak sangat menggangu kehidupan individu sehari-hari.Mengingat hal itu maka pada penelitian ini akan dibuat sebuah aplikasi untuk dapat mengidentifikasi mengidap fobia atau tidak. Observasi akan dilakukan melalui kusioner. Dengan setiap jawaban akan mempunyai nilai terhadap gejala-gejala fobia tersebut. Tahap pertama adalah pengambilan data. Dari 45 responden didapatkan data kuesioner yang kemudian dengan statistik melalui sistem.Aplikasi ini akan memberikan informasi persentase kecenderungan fobia yang dimiliki seseorang.

Dalam pembuatan sistem pakar fobia mengacu pada penggunaan pedoman DSM-5. DSM-5 adalah Diagnostic and Statistical Manual of Mental Disorders (DSM) yang diterbitkan oleh American Psychiatric Association (APA) yang menawarkan bahasa yang umum dan kriteria standar untuk klasifikasi gangguan mental. Buku ini digunakan, atau diandalkan, oleh dokter, peneliti, lembaga regulasi obat kejiwaan, perusahaan asuransi kesehatan, perusahaan farmasi, sistem hukum, dan pembuat kebijakan bersama-sama dengan alternatif seperti Klasifikasi Statistik Internasional Penyakit dan Masalah Kesehatan Terkait (ICD), diproduksi oleh Organisasi Kesehatan Dunia (WHO). DSM sekarang dalam edisi kelima, DSM-5, yang diterbitkan pada 18 Mei 2013 (Maulana, 2018).

\section{TINJAUAN PUSTAKA}

Dalam penelitian mengenai Sistem Pakar Berbasis Web Untuk Diagnosa Penyakit Pada Tanaman Anggrek Menggunakan Metode Certainty Factor, berdasarkan hasil analisis, perancangan, dan implementasi, maka telah berhasil dibangun sebuah sistem pakar yang dapat digunakan untuk mendiagnosa hama dan penyakit pada tanaman anggrek dan memberikan cara penanggulangannya. Sistem ini telah dilengkapi dengan metode Certainty Factor untuk mengukur nilai kepastian dari suatu hipotesa terhadap suatu fakta. Dengan adanya pembatasan hak akses yang diterapkan pada sistem, admin bertugas penting untuk mengolah data, seperti menambah, mengubah, dan menghapus data. Sedangkan pengguna hanya dapat melakukan konsultasi terhadap sistem dan pakar, serta melihat informasi yang tersedia (Yuwono, Wahyuningsih, dan Hafsah , 2014).

Dalam penelitian mengenai Pengembangan Sistem Pakar untuk Diagnosis Penyakit Hepatitis Berbasis Web Menggunakan Metode Certainty Factor. Sistem mampu mengeluarkan hasil diagnosa yang sama dengan pakar dengan akurasi $95 \%$. Uji coba telah dilakukan kepada salah satu pasien yang menderita hepatitis dan memiliki hasil yang sama dengan diagnosa pakar (Ramdhani, Isnanto, dan Perti, 2015).

Dalam penelitian mengenai Sistem Pakar Diagnosa Penyakit Pada Burung Kenari Dengan Metode Certainty Factor Sistem pakar, penelitian ini didasarkan dari data yang diperoleh dari seorang dokter hewan. Gejalagejala dari penyakit burung lovebird diformulasikan dalam sistem pakar melalui metode Certainty Factor. Untuk mendapatkan solusi yang tepat dalam menangani penyakit burung kenari dengan melakukan konsultasi menggunakan sistem pakar yang telah dikembangkan dan memiliki hasil persentase sebesar 99\% (Rahmawati, Puspitasari, dan Pradibta, 2015).

Dalam penelitiannya Sistem Pakar Diagnosis Dini Penyakit Leukemia Dengan Metode Certainty Factor, Sistem ini bekerja dengan mengadaptasi pengetahuan dan "kreativitas" dokter dalam mengobati pasien serta didukung dengan literatur-literatur yang berkaitan dengan penyakit leukimia, baik dari buku-buku kedokteran maupun dari internet. Setelah mengamati dan mencari informasi baik dari pakar (dokter) maupun pengguna (pasien), diketahui bahwa jenis penyakit leukimia memiliki berbagai macam gejala yang sangat komplek dan beberapa penyakit memiliki gejala yang hampir sama. Pengambilan kesimpulan identifikasi dihitung menggunakan metode Certainty Factor dengan menggunakan data gejala dari pengguna. Sistem pakar identifikasi dini penyakit leukimia mampu mendiagnosis gejala penyakit leukimia sebesar 78\% (Ghozali dan Eviyanti, 2016).

Dalam penelitian mengenai Sistem Pakar Diagnosa Penyakit Ibu Hamil Menggunakan Metode Certainty Factor (CF), pengujian sistem pakar diagnosa penyakit ibu hamil menggunakan metode Certainty Factor 
dilakukan dengan dua tahap yaitu pengujian validasi dan pengujian akurasi. Pengujian Validasi berfungsi untuk mengetahui apakah sistem yang telah dibangun sesuai dengan yang dibutuhkan. Pengujian validasi ini menggunakan metode pengajuan black box karena tidak memfokuskan terhadap alur algoritma program melainkan lebih menekankan dalam menemukan kesesuaian antara kinerja sistem dengan daftar kebutuhan. Pada setiap kebutuhan dilakukan proses pengujian untuk mengetahui keesuaian antara kebutuhan dan kinerja sistem. Delapan kasus uji yang telah dilakukan dengan menggunakan pengujian black box menunjukkan bahwa nilai valid sistem pakar diagnosa penyakit ibu hamil sebesar $100 \%$ yang menandakan fungsionalitas sistem berjalan sesuai dengan daftar kebutuhan sistem. Data yang diuji berjumlah 13 sampel data analisa pakar. Dan dibandingkan dengan metode yang sebelumnya yang menggunakan metode forward caining yang keakurasiannya sebesar $86,33 \%$, terbukti bahwa dengan menggunakan metode Certainty Factor lebih efektif dalam memecahkan sebuah masalah (Aji, Furqon, dan Widodo, 2017).

Dalam penelitian mengenai Sistem Pakar Diagnosa Penyakit Pada Burung Lovebird Menggunakan Metode Certainty Factor dengan menerapkan metode Certainty Factor, aplikasi ini mampu memberikan informasi mengenai penyakit pada burung lovebird kepada pengguna melalui gejalagejala yang di-input-kan oleh pengguna ke sistem, juga dapat memberikan informasi mengenai solusi penanganan penyakit yang diderita burung lovebird (Triambudi, Sanjaya, dan Nurlifa, 2018).

Dalam penelitian mengenai Sistem Pakar Pengembangan Skala Minat Karir Mahasiswa Dengan Inferensi Fuzzy Tsukamoto, Dalam penelitian ini, peneliti bertujuan membuat sistem pakar yang dapat memberikan gambaran tentang skala pengembangan minat karir mahasiswa dengan metode fuzzy logic yang mana membutuhkan beberapa variabel yaitu realistic, investigative, artistic, social, enterprise dan conventional yang mana di masing-masing variabel akan diambil nilai z-score. Berdasarkan hasil pengujian yang telah dilakukan dengan 100 data skala minat karir mahasiswa, dapat disimpulkan bahwa implementasi metode fuzzy Tsukamoto memperoleh total akurasi sebesar
$67 \%$ data yang sesuai dan 33\% data yang tidak sesuai (S dan Purnomo, 2018).

Sistem pakar adalah salah satu cabang ilmu AI (Artificial Intelligent) yang membuatpenggunaan secara luas knowledge yangkhusus untuk penyelesaian masalah tingkatmanusia yang pakar. Seorang pakar adalahorang yang mempunyai keahlian dalambidang tertentu, yaitu pakar yang mempunyai knowledge atau kemampuan khusus yangorang lain tidak mengetahui atau mampu dalam bidang yang dimilikinya (Arhami, 2005).

Certainty Factor (CF) merupakan sebuah metode yang diusulkan oleh Shortliffe dan Buchanan pada 1975 untuk mengakomodasi ketidakpastian pemikiran (inexactreasoning) seorang pakar. Seorang pakar (contoh: dokter) sering menganalisi informasi dengan ungkapan "mungkin", "kemungkinan besar", "hampir pasti". Sehingga dengan adanya metode Certainty Factor ini dapat mengambarkan tingkat keyakinan seorang pakar terhadap masalah yang sedang dihadapi (Kiswanto, 2014).

Untuk menghitung nilai Certainty Factor dapat dilihat pada Persamaan 1.

$C F[H, E]=M B[H, E]-M D[H, E]$

Keterangan :

$\mathrm{CF}[\mathrm{H}, \mathrm{E}] \quad$ : Certainty Factorhipotesa yang dipengaruhi oleh evidence e yang diketahui dengan pasti

MB [H,E] : Measure of belief terhadap hipotesa $\mathrm{H}$, jika diberikan evidence $\mathrm{E}$ (antara 0 dan 1$)$

MD : Measure of Disbelief (Nilai Ketidakpercayaan)

P : Probability

E : Evidence ( Peristiwa / Fakta)

Untuk Menghitung nilai $\mathrm{CF}_{\text {gejala }}$ dapat dilihat pada Persamaan 2.

$$
C F_{\text {gejala }}=C F_{\text {user }} x C F_{\text {pakar }}
$$

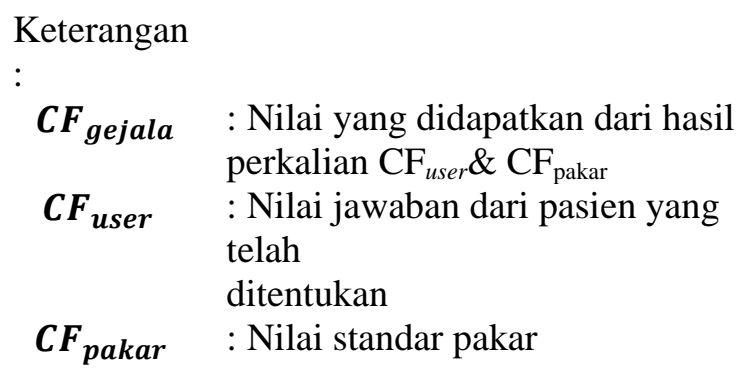


Untuk menghitung nilai $\mathrm{CF}_{\text {combine }}$ dapat dilihat pada Persamaan 3.

$$
C F_{\text {Combine }}=C F_{\text {old }}+C F_{\text {gejala }} x\left(1-C F_{\text {old }}\right)
$$

\section{Keterangan}

$$
\begin{array}{ll}
\boldsymbol{C F}_{\text {Combine }} & : \mathrm{CF}_{\text {combine }} \text { atau } \mathrm{CF}_{\text {gabungan }} \\
& \text { digunakan apabila gejala } \\
& \text { lebih dari 1 } \\
\boldsymbol{C F}_{\text {old }} & : \mathrm{CF}_{\text {old }} \text { atau nilai } \mathrm{CF}_{\text {lama }} \\
\boldsymbol{C F}_{\text {gejala }} \boldsymbol{x} & \text { : Nilai CF berdasarkan gejala }
\end{array}
$$

Untuk menghitung $\mathrm{CF}_{\text {persentase }}$ dapat dilihat pada Persamaan 4.

$$
C F_{\text {presentase }}=C F_{\text {combine }} x 100 \%
$$

Keterangan :

$$
\begin{array}{cl}
\boldsymbol{C} \boldsymbol{F}_{\text {presentase }} & : \text { Nilai } \mathrm{Cf} \text { dalam persen }(\%) \\
\boldsymbol{C F}_{\text {combine }} & : \text { Besaran nilai } \mathrm{CF}_{\text {combine }}
\end{array}
$$

\section{METODOLOGI PENELITIAN}

Secara garis besar proses jalannya penelitian ini dibagi menjadi empat tahapan, yaitu : (1) Akuisisi Pengetahuan, (2) Representasi Pengetahuan, (3) Inferensi Pengetahuan dan (4) Pemindahan Pengetahuan. Flowchart jalannya penelitian dapat dilihat pada Gambar 1.
Metode Certainty Factor

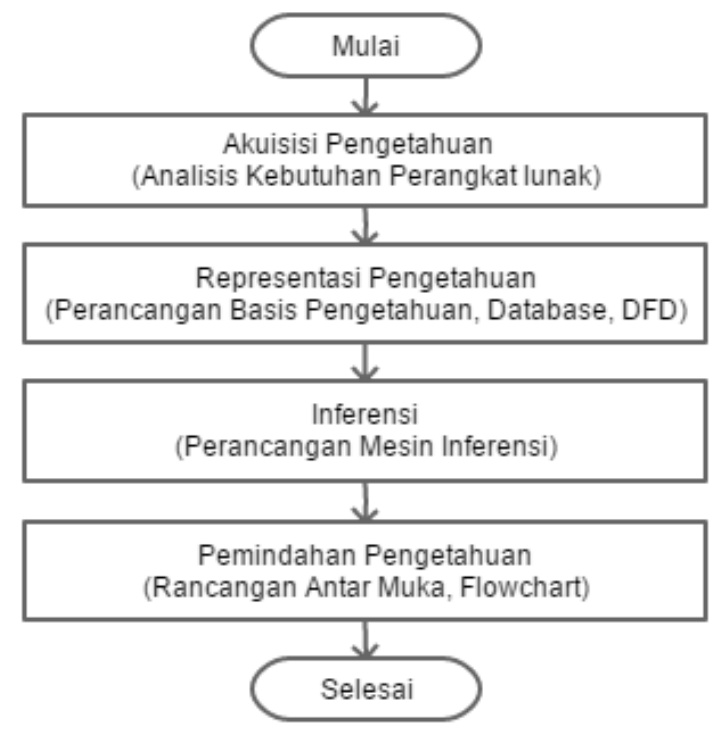

Gambar 1. Jalan Penelitian

\subsection{Akuisisi Pengetahuan}

Akuisisi Pengetahuan merupakan kegiatan untuk mencari dan mengumpulkan data untuk analisis kebutuhan perangkat lunak.

\subsection{Representasi Pengetahuan}

\subsubsection{Perancangan Data Flow Diagram}

Data flow diagram Level 0 dalam penelitian ini dapat dilihat pada Gambar 2.

\subsubsection{Perancangan Basis Pengetahuan}

Dasar pengetahuan merupakan inti dari program sistem pakar karena merupakan presentasi pengetahuan yang menyimpan dasar-dasar aturan dan data tentang fobia yang bersumber dari pakar. Berikut ini adalah proses indexing yang digunakan dalam aplikasi ini dapat dilihat pada Tabel 1.

Tabel 1. Jenis Fobia

\begin{tabular}{cll}
\hline Kode & \multicolumn{1}{c}{ Jenis Fobia } \\
\hline F1 & Mengemudi, terbang, terowongan, jembatan atau ruang tertutup & Situational Phobia \\
F2 & Hewan atau serangga & Animal Phobia \\
F3 & Ketinggian, badai, air & Natural Phobia \\
F4 & Darah, jarum atau suntikan & Medical phobia \\
F5 & Tersedak atau muntah, cinta, kegagalan, sendiri, kebahagiaan & Abstrak Phobia \\
& This test based on APA, DSM-5 \\
\hline
\end{tabular}

Dari Tabel 2 akan didapatkan nilai yang akan menyimpulkan tingkat fobia yang dialami oleh seorang pasien. Dengan syarat bahwa pasien telah mengalami gejala-gejala tersebut selama minimal 7 hari.

\subsubsection{Perancangan Database}

Relasi tabel dalam penelitian ini dapat dilihat pada Gambar 3. 
Tabel 2. Gejala dan Bobot

\begin{tabular}{|c|c|c|}
\hline Kode & Gejala Fobia & Bobot \\
\hline G1 & Merasakan saat-saat teror, ketakutan atau ketakutan dalam situasi ini & 0.4 \\
\hline G2 & Merasa cemas, khawatir atau gugup & 0.4 \\
\hline G3 & $\begin{array}{l}\text { Mempunyai pikiran bahwa akan disakiti, diikuti dengan rasa takut atau hal-hal buruk } \\
\text { yang akan terjadi }\end{array}$ & 0.1 \\
\hline G4 & Merasakan hati berdebar, berkeringat, kesulitan bernapas, pingsan atau gemetar & 0.4 \\
\hline G5 & $\begin{array}{l}\text { Merasakan otot yang tegang, terasa seperti di ujung tanduk atau gelisah, kesulitan } \\
\text { bersantai }\end{array}$ & 0.4 \\
\hline G6 & Mencoba menghindari atau tidak mendekati atau masuk dalam situasi seperti ini & 0.3 \\
\hline G7 & Menjauh atau berusaha pergi atau menghindar dari awal & 0.3 \\
\hline G8 & $\begin{array}{l}\text { Menghabiskan banyak waktu untuk mempersiapkan atau menunda-nunda jika } \\
\text { harusmenghadapi }\end{array}$ & 0.3 \\
\hline G9 & Mengalihkan perhatian saya untuk menghindari untuk memikirkan & 0.3 \\
\hline G10 & $\begin{array}{l}\text { Memerlukan Bantuann untuk mengatasi situasi ini (spt. Alkohol atau obat-obatan, } \\
\text { takhayul benda, orang lain) }\end{array}$ & 0.1 \\
\hline
\end{tabular}

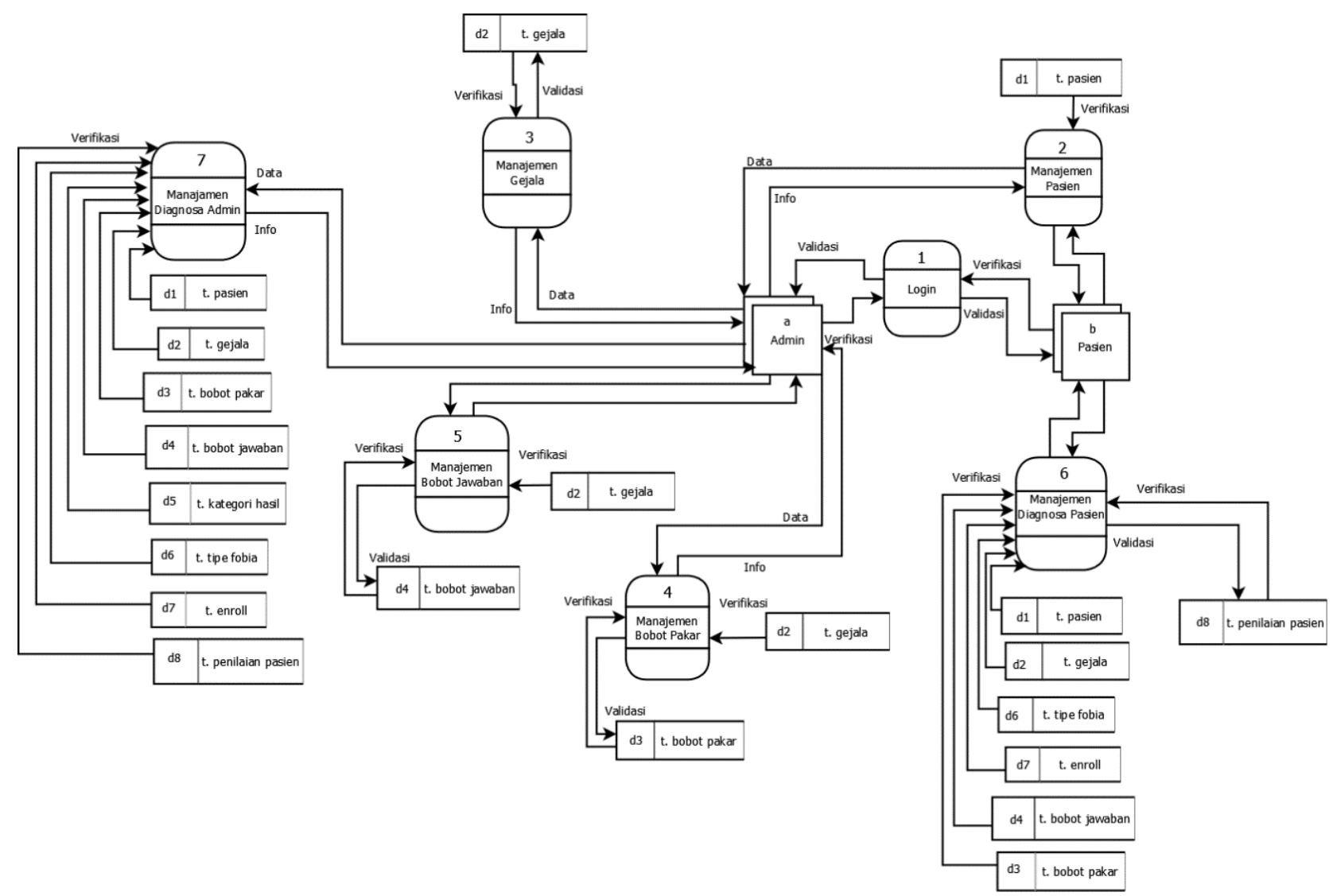

Gambar 2. Data Flow Diagram Level 0

\subsection{Inferensi Pengetahuan}

Dalam perancangan sistem pakar dengan menggunakan Certainty Factor dimulai dari perhitungan nilai Certainty Factor gejala kemudian dilanjutkan proses perhitungan
$C F_{\text {combine }}$ dan terakhir adalah proses persentase $C F_{\text {combine }}$ untuk menentukan tingkat fobia.

\subsection{Pemindahan Pengetahuan}

Perancangan jalannya sistem dapat dilihat pada Gambar 4. 

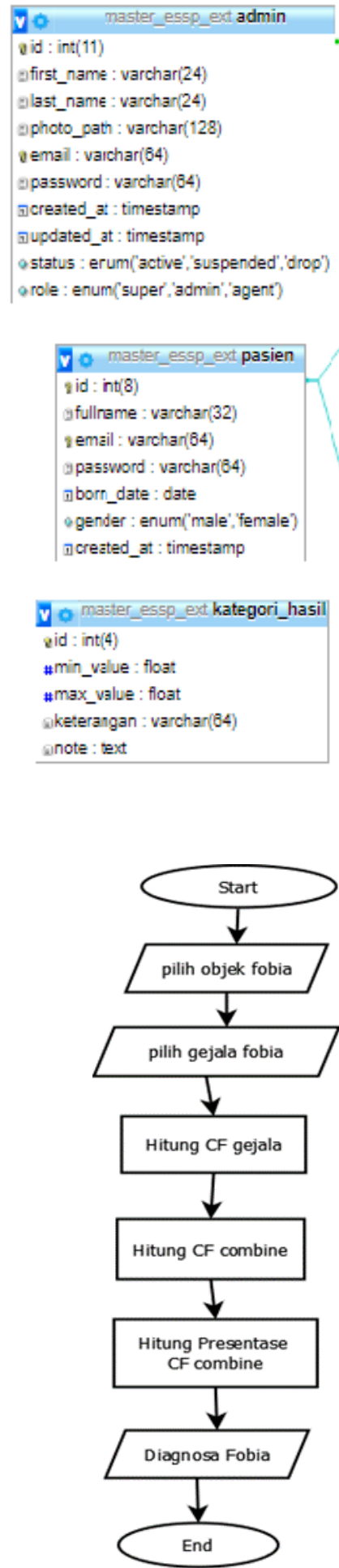

Gambar 4. Flowchart Sistem

\section{PEMBAHASAN \\ 4.1 Pembahasan}

Berikut ini contoh pengujian dengan perhitungan Certainty Factor. Dalam hal ini mengambil salah satu sampel data kasus dapat dilihat pada Tabel 3. Langkah perhitungan sebagai berikut.

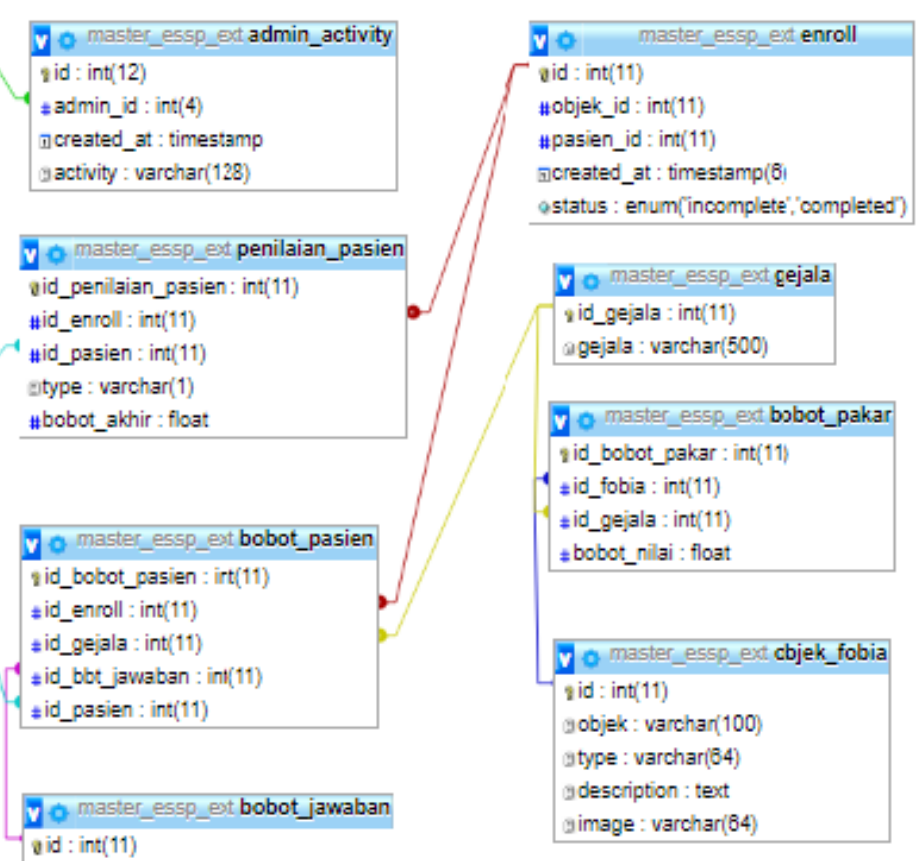

\# bobot_nilai : float

Gambar 3. Relasi Database

1. Mencari nilai CF dengan menggunakan Persamaan 2, hasilnya dapat dilihat pada Tabel 3 .

Tabel 3. Nilai CF

\begin{tabular}{cccc}
\hline Gejala & $\begin{array}{c}\text { Bobot } \\
\text { Pasien }\end{array}$ & $\begin{array}{c}\text { CF } \\
\text { Pakar }\end{array}$ & $\begin{array}{c}\text { CF } \\
\text { Gejala }\end{array}$ \\
\hline G1 & 0.3 & 0.4 & 0.12 \\
G2 & 0.3 & 0.4 & 0.12 \\
G3 & 0.3 & 0.1 & 0.03 \\
G4 & 0.1 & 0.4 & 0.04 \\
G5 & 0.3 & 0.4 & 0.12 \\
G6 & 0.3 & 0.3 & 0.09 \\
G7 & 0.3 & 0.3 & 0.09 \\
G8 & 0.3 & 0.3 & 0.09 \\
G9 & 0.3 & 0.3 & 0.09 \\
G10 & 0.1 & 0.1 & 0.01 \\
\hline
\end{tabular}

2. Mencari nilai $\mathrm{CF}_{\text {Combine }}$ menggunakan Persamaan 3.

CF Combine $_{1}=0.12+0.12 x(1-0.12)=0.22$

CF Combine $_{2}=0.22+0.03 x(1-0,22)=0.24$

CF Combine ${ }_{3}=0.24+0.04 x(1-0.24)=0.27$

CF Combine ${ }_{4}=0.27+0.12 x(1-0,27)=0.36$

CF Combine ${ }_{5}=0.36+0.09 x(1-0.36)=0.42$

CF Combine ${ }_{6}=0.42+0.09 x(1-0.42)=0.48$

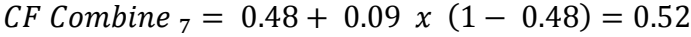

CF Combine ${ }_{8}=0.52+0.09 \times(1-0,52)=0.56$

CF Combine ${ }_{9}=0.56+0.01 \times(1-0,56)=0.569$ 
Tabel 4. Contoh Pengujian

\begin{tabular}{|c|c|c|c|c|c|c|c|c|c|c|c|c|c|c|c|}
\hline \multirow{2}{*}{ Nama } & \multirow{2}{*}{$\begin{array}{l}\text { Objek } \\
\text { Fobia }\end{array}$} & \multirow{2}{*}{ Email } & \multirow{2}{*}{$\begin{array}{l}\text { Tgl } \\
\text { lahir }\end{array}$} & \multicolumn{10}{|c|}{ Jawaban Kuesioner Pasien } & \multicolumn{2}{|c|}{ Hasil } \\
\hline & & & & G1 & G2 & G3 & G4 & G5 & G6 & G7 & G8 & G9 & G10 & & \\
\hline \multirow{4}{*}{$\begin{array}{l}\text { Vina } \\
\text { Yani }\end{array}$} & \multirow{4}{*}{$\begin{array}{l}\text { R. } \\
\text { tertutup }\end{array}$} & $\begin{array}{l}\text { vina2life@g } \\
\text { mail.com }\end{array}$ & $\begin{array}{l}05 / 02 / \\
1984\end{array}$ & SR & SR & SR & KK & SR & SR & SR & SR & SR & KK & & \\
\hline & & \multicolumn{2}{|c|}{ Bobot jawaban } & 0.3 & 0.3 & 0.3 & 0.1 & 0.3 & 0.3 & 0.3 & 0.3 & 0.3 & 0.1 & 2.6 & Berat \\
\hline & & \multicolumn{2}{|c|}{ CF gejala } & 0.12 & 0.12 & 0.03 & 0.04 & 0.12 & 0.09 & 0.09 & 0.09 & 0.09 & 0.01 & & \\
\hline & & \multicolumn{2}{|c|}{ CF combine } & 0.22 & 0.24 & 0.27 & 0.36 & 0.42 & 0.47 & 0.52 & 0.56 & 0.56 & 0.56 & $57 \%$ & Berat \\
\hline
\end{tabular}

3. Selanjutnya dicari persentase keyakinan dengan meggunakan Persamaan 4.

$$
C F_{\text {presentase }}=0.569 \times 100 \%=57 \%
$$

Berdasarkan tabel kategori diagnosa fobia, dengan hasil perhitungan sebesar $57 \%$, maka dapat disimpulkan bahwa tingkat fobia adalah Berat.

\subsection{Validasi Hasil}

Berdasarkan 45 data yang telah diuji terhadap pasien, didapati bahwa data telah sesuai dengan hasil yang dibuat oleh pakar seperti terlihat pada Tabel 5 .

Tabel 5. Persentase Validasi Hasil Uji Sistem

\begin{tabular}{ccc}
\hline Validasi sistem & Jumlah & Persentase \\
\hline Sesuai & 45 & $100 \%$ \\
Tidak Sesuai & 0 & $0 \%$ \\
Total Persentase & $100 \%$ \\
\hline
\end{tabular}

\section{KESIMPULAN}

Berdasarkan 45 data yang telah diujikan terhadap pakar dan sistem didapatkan 4 pasien yang tidak terkena fobia, untuk pasien yang terkena fobia ringan adalah 16 pasien, pasien dengan fobia sedang adalah 21 pasien, pasien dengan fobia berat adalah 4 pasien. Sedangkan untuk kesesuaian pengujian antara hasil dan validasi pakar (psikolog) dan sistem diperoleh persentase keberhasilan sebesar 100\%.

Saran untuk penelitian lanjutan adalah diperlukan adanya pengembangan terhadap sistem pakar ini berdasarkan dari pengembangan penelitian pada DSM-V revisi selanjutnya, serta perlu ditambahkan saransaran penanganan dan pengobatan terhadap masing-masing diagnosis.

\section{DAFTAR PUSTAKA}

Aji, A. H., Furqon, M. T., dan Widodo, A. W. (2017, Agustus 31). Sistem Pakar Diagnosa Penyakit Ibu Hamil Menggunakan Metode Certainty Factor (CF). Jurnal Pengembangan Teknologi
Informasi dan Ilmu Komputer, ISSN : 2548-964X, ol. 2, No. 5, 2127-2134. Dipetik 2018, dari http://jptiik.ub.ac.id/index.php/jptiik/article/view/1556

Arhami, M. (2005). Konsep Dasar Sistem Pakar. Yogyakarta: Andi.

Ghozali, M. F., dan Eviyanti, A. (2016, 11). Sistem Pakar Diagnosis Dini Penyakit Leukemia Dengan Metode Certainty Factor. Kinetik Universitas Muhamadiyah Sidoarjo, ISSN : 25032267, Vol.1, No.3, Vol 1, 135-146. Diambil kembali dari http://kinetik.umm.ac.id/index.php/kinet ik/article/view/122/17

Kiswanto, B. H. (2014, Oktober 28). Metode Certainty Factor (CF). Dipetik Desember 12, 2018, dari Yuk Belajar Online: http://yuk-belajaronline.blogspot.com/2014/10/metodecertainty-factor-cf.html

Maulana, I. A. (2018, Juni 2). Diagnostic and Statistical Manual of Mental Disorders. Dipetik Desember 15, 2018, dari wikipedia.org:

https://id.wikipedia.org/wiki/Diagnostic _and_Statistical_Manual_of_Mental_Di sorders

Rahmawati, A., Puspitasari, D., dan Pradibta, H. (2015). Sistem Pakar Diagnosa Penyakit Pada Burung Kenari Dengan Metode Certainty Factor. Jurnal Informatika Polinema, Vol.1 , No. 2, ISSN : 2407-070X, 53.

Ramdhani, A., Isnanto, R. R., dan Perti, I. (2015). Pengembangan Sistem Pakar untuk Diagnosis Penyakit Hepatitis Berbasis Web Menggunakan Metode Certainty Factor. Jurnal Teknologi dan Sistem Komputer, ISSN : 2338-0403, Vol. 3, No 1, 58-64.

S, T. A., dan Purnomo, A. S. (2018). Sistem Pakar Pengembangan Skala Minat Karir 
Mahasiswa Dengan Inferensi Fuzzy Tsukamoto. Seminar Nasional Multimedia \& Artificial Intelligence (hal. 156-162). Yogyakarta: FTI Universitas Mercu Buana Yogyakarta.

Triambudi, M. H., Sanjaya, K. T., dan Nurlifa, A. (2018). Sistem Pakar Diagnosa Penyakit Pada Burung Lovebird. Prosiding Seminar Nasional Hasil Penelitian dan Pengabdian kepada Masyarakat III, ISSN : 2580-3921, 377380.
Yunita, R. (2018). Makalah Phobia. Scribd.com. Diambil kembali dari https://id.scribd.com/document/3846466 23/Makalah-Phobia

Yuwono, B., Wahyuningsih, W. P., dan Hafsah . (2014). Sistem Pakar Berbasis Web Untuk Diagnosa Penyakit Pada Tanaman Anggrek Menggunakan Metode Certainty Factor. Seminar Nasional Informatika 2014 (semnasIF 2014), ISSN : 1979-2328, 209. 